Res., Soc. Dev. 2019; 8(7):e11871106

ISSN 2525-3409 | DOI: http://dx.doi.org/10.33448/rsd-v8i7.1106

\title{
Desempenho de estudantes de Educação Física em Educação Inclusiva no Enade/Brasil
}

Knowledge of Physical Education students on Inclusive Education Enade/Brazil

Desempeño de estudiantes de Educación Física en Educación Inclusiva en el

Enade/Brasil

Recebido: 09/04/2019 | Revisado: 28/04/2019 | Aceito: 09/05/2019 | Publicado: 16/05/2019

Antonio Evanildo Cardoso de Medeiros Filho

ORCID: https://orcid.org/0000-0002-4442-162X

Universidade Regional do Cariri (URCA), Brasil

E-mail: evanildofilho17@gmail.com

José Airton de Freitas Pontes Junior

ORCID: https://orcid.org/0000-0003-2045-2461

Universidade Estadual do Ceará (UECE), Brasil

E-mail: jose.airton@uece.br

Luciana Fialho Rocha Santa Rosa

ORCID: https://orcid.org/0000-0002-5949-6309

Universidade Estadual do Ceará (UECE), Brasil

E-mail: profluciana.fialho@gmail.com

Kélvia Sena de Santana

ORCID: https://orcid.org/0000-0002-9907-7184

Universidade Estadual do Ceará (UECE), Brasil

E-mail: kelviasena@hotmail.com

Rita de Cássia Barbosa Paiva Magalhães

ORCID: https://orcid.org/0000-0001-9052-2395

Universidade Federal do Rio Grande do Norte (UFRN), Brasil

E-mail: ritafora@hotmail.com

\section{Resumo}

A pesquisa teve como objetivo avaliar os conteúdos e o desempenho de estudantes de Educação Física em questões de Educação Inclusiva no Exame Nacional de Desempenho dos Estudantes (Enade/Inep). Para isso, o estudo se divide em duas etapas: revisão integrativa que fundamenta o contexto da formação e atuação dos professores de Educação Física na Educação Inclusiva de pessoas deficientes e análise psicométrica das questões acerca de 
Educação Inclusiva de pessoas deficientes nas edições do Enade (2004 a 2017). Na revisão integrativa identificamos ausência de formação específica, inexistência de trabalho multidisciplinar e necessidades de novos recursos. Na análise psicométrica observou-se a maioria dos itens com índices de facilidade médio e difícil, índices de discriminação bom ou muito bom e nos níveis aplicar ou superior na Taxonomia de Bloom Revisada. Observou-se maior desempenho entre os estudantes do gênero feminino, IES pública e das regiões Nordeste e Norte. Entendendo o Enade como um mecanismo importante na verificação de desempenho na formação inicial, torna-se necessário maior envolvimento das IES e dos estudantes com os conhecimentos que fundamentam essa temática no contexto acadêmico e na intervenção social, visto que a prova apresenta boa organização e a literatura indica a importância dessa formação.

Palavras-chave: Educação inclusiva; Ensino Superior; Profissão docente.

\begin{abstract}
The aim of this paper was to evaluate the Physical Education students' contents and performance about Inclusive Education on the National Exam of Student Performance (Enade/Inep). For this, the study is divided into two stages: an integrative review, which grounds the context about Physical Education teachers' formation and performance on Inclusive Education of disabled people and psychometric analysis of the questions about Inclusive Education on Enade (2004 to 2017). In the integrative review, the absence of specific training, lack of multidisciplinary work and needs of new resources could be identified. In the psychometric analysis, most of the items indicating medium and difficult rates, discrimination rates good or very good, also the level applying or higher in Bloom's Taxonomy Revised were also observed. Higher performance was observed among students who were female, studied in public HEI and also were from the Northeast and North regions. Understanding the Enade as an important mechanism in verifying the performance in initial formation, it is necessary a better involvement between HEIs and students with the knowledge which grounds this theme in the academic context and in social intervention, since the exam is well organized and its literature indicates the importance of this training.
\end{abstract}

Keywords: Inclusive education; Higher Education; Teaching profession.

\title{
Resumen
}

La investigación tuvo como objetivo evaluar los contenidos y el desempeño de estudiantes de Educación Física en cuestiones de Educación Inclusiva en el Examen Nacional de Evaluación 
del Desempeño de Estudiantes (ENADE/ Inep). Por eso, el estudio se divide en dos etapas: revisión integrativa que fundamenta el contexto de la formación y actuación de los profesores de Educación Física en la Educación Inclusiva de personas discapacitadas y análisis psicométrico de las cuestiones acerca de Educación Inclusiva de personas con discapacidad en las ediciones del Enade (2004 a 2017). En la revisión integrativa identificamos ausencia de formación específica, inexistencia de trabajo multidisciplinario y necesidades de nuevos recursos. En el análisis psicométrico se observó la mayoría de los ítems con índices de facilidad mediana y difícil, índices de discriminación bueno o muy bueno y en los niveles aplicar o superior en la Taxonomía de Bloom Revisada. Se observó mayor desempeño entre los estudiantes del género femenino, IES pública y de las regiones Nordeste y Norte. Entendiendo el Enade como un mecanismo importante en la verificación de desempeño en la formación inicial, se hace necesaria una mayor participación de las IES y de los estudiantes con los conocimientos que fundamentan esa temática en el contexto académico y en la intervención social, ya que la prueba presenta buena organización y la literatura indica la importancia de esta formación.

Palabras clave: Educación inclusiva; Educación superior; Profesión docente.

\section{Introdução}

A Educação Inclusiva se configura como um dos grandes desafios na formação e atuação de professores. Assim como em Noronha e Pinto (2014) a Educação Inclusiva será considerada nesse estudo como processo que oportuniza a participação de todos os estudantes do ensino regular, permeado por uma reestruturação da cultura escolar, das práticas pedagógicas, das ações realizadas na escola, da capacitação de recursos humanos e da infraestrutura de forma a responder às diversidades dos alunos. Uma abordagem democrática, que percebe o sujeito, assim como suas particularidades tendo como objetivos principais o desenvolvimento pessoal e a inserção na sociedade.

Cabe, assim, que a perspectiva da Educação Inclusiva, ganhou destaque no contexto educacional, político e social em documentos, tais como: a: i) Lei de Diretrizes Bases da Educação Nacional n 9.394/96 (Brasil, 1996), ii) Política Nacional de Educação Especial na 
Perspectiva da Educação Inclusiva (PNEEPEI), iii) Direitos das Pessoas com Deficiência (Brasil, 2009), iv) Diretrizes Curriculares Nacionais Gerais para a Educação Básica (Brasil, 2010) e o próprio v) Plano Nacional da Educação (Brasil/PNE, 2014-2024).

No Brasil, existe um conjunto de leis e políticas educacionais defendendo o princípio de que a educação de qualidade seja um direito de todos, devendo ser considerada e respeitada às especificidades de cada indivíduo. Como afirmam Silva Neto et al. (2018), o envolvimento da comunidade escolar, na tentativa de entender o processo de inclusão não se limita apenas a relação estabelecida entre o professor e o aluno. Relaciona-se, ainda, com a perspectiva de que a escola não molda o aluno a uma dada configuração curricular, mas oferece respostas educativas diversificadas construídas na perspectiva de que todos os estudantes podem aprender juntos em um currículo diferenciado.

Surgem preocupações dos profissionais de educação, pois se sabe que muitas escolas ainda ofertam um ensino predominantemente excludente, sendo agravado pela precária estrutura física, bem como os aspectos didático-pedagógicos e da formação docente insatisfatória para atender os diferentes públicos (Gomes, 2011; Tebaldi, 2014).

Esses últimos aspectos são os que mais serão discutidos nesse estudo, especificamente na área de Educação Física, em que foi um dos primeiros cursos a ofertar nas matrizes curriculares das disciplinas conteúdos direcionadas ao atendimento de pessoas com deficiência. Aproveita-se para destacar a importância da Educação Superior enquanto meio para a produção do conhecimento e a necessidade de serem vivenciados os valores e as práticas da Educação Inclusiva (Pletsch \& Souza, 2017).

O conteúdo de Educação Inclusiva também vem compondo a matriz curricular das avaliações em larga escala, como é caso das provas destinadas às licenciaturas no Exame Nacional de Desempenho dos Estudantes (Enade). Entretanto, apesar dos incentivos e 
avanços no processo de inclusão escolar, são raros os estudos que relacionam formação docente com Educação Inclusiva (Sousa, 2017).

Com base no que está exposto, estudos acerca da formação e atuação de professores para atuar na Educação Inclusiva podem contribuir para fomentar a necessidade e importância de aprimorar a formação dos professores de Educação Física para desempenhar suas ações face a esse modelo educacional.

A relevância aplicada a essa temática é potencializada de acordo o crescimento dos alunos em escolas regulares e classes comuns em que aumentou 118\% de 2007 a 2014, bem como pela a meta 4 do PNE (Brasil/PNE, 2014) que tem a intenção de "aumentar a porcentagem de alunos com deficiência, transtornos globais do desenvolvimento e altas habilidades ou superdotação matriculados na rede regular de ensino".

Este artigo tem como objetivo geral avaliar os conteúdos e o desempenho de estudantes de Educação Física em questões de Educação Inclusiva no Exame Nacional de Desempenho dos Estudantes (Enade/Inep). Para isso, formulou-se os seguintes objetivos específicos: a) elaborar uma revisão integrativa na intenção de apresentar os principais apontamentos das produções científicas acerca da formação e atuação dos professores de Educação Física na Educação Inclusiva de pessoas deficientes, b) analisar de forma psicométrica as questões acerca de Educação Inclusiva de pessoas deficientes nas edições do Enade (2004 a 2017) e c) verificar o desempenho dos estudantes no referido Exame nas questões sobre Educação Inclusiva de pessoas deficientes.

\section{Metodologia}

Nessa seção inicialmente será apresentada a metodologia utilizada no primeiro momento do estudo, ou seja, a revisão integrativa, e logo após, será apresentada a 
Res., Soc. Dev. 2019; 8(7):e11871106

ISSN 2525-3409 | DOI: http://dx.doi.org/10.33448/rsd-v8i7.1106

metodologia utilizada com os microdados do Enade, os quais nos possibilitou verificar o desempenho dos estudantes de Educação Física nas questões sobre Educação Inclusiva.

\subsection{Metodologia da Revisão integrativa}

O presente estudo de revisão integrativa seguiu as orientações de Galvão, Pansani e Harrad (2015). O método é composto por 6 etapas. Tais etapas correspondem, respectivamente, "estabelecimento de hipótese ou questão de pesquisa"; "amostragem ou busca na literatura"; Categoria dos estudos; "Avaliação dos estudos incluídos na revisão"; "Interpretação dos resultados" e "síntese do conhecimento ou apresentação da revisão".

Desse modo, foi desenhada a seguinte pergunta de partida: Quais os principais apontamentos das produções científicas acerca da formação e atuação dos professores de Educação Física na Educação Inclusiva de pessoas deficientes? Como critérios de inclusão, optou-se por artigos científicos completos, dissertação de mestrado, tese de doutorado, publicados entre o ano de 2011 a 2017. Esse recorte temporal considerou as orientações de Galvan (2017). Foram excluídos estudos que utilizaram métodos de revisões de literatura em qualquer um de suas abordagens (narrativa, integrativa, sistemática) e que não atenderam o recorte temporal.

As bases e repositórios de dados consultadas para as buscas das produções científicas foram: Scientific Electronic Library Online (SciELO), Literatura Latino-Americana e do Caribe em Ciências da Saúde (LILACS), Education Resources Information Centere (ERIC) Biblioteca Digital Brasileira de Teses e Dissertações (BDTD). Para as buscas foi utilizado o operador Booleano "and" e "or" na intenção de sistematizar as buscas com os seguintes descritores: Formação Acadêmica; Formação docente; professores; Educação Física; Educação Inclusiva; Educação Física Escolar; Pessoas com deficiência; Alunos com deficiência; Educação Básica. 
Res., Soc. Dev. 2019; 8(7):e11871106

ISSN 2525-3409 | DOI: http://dx.doi.org/10.33448/rsd-v8i7.1106

\subsection{Metodologia de análise dos microdados e psicométrica das questões}

No segundo momento realizou-se uma pesquisa descritiva, exploratória, quantitativa e documental (Pereira, Shitsuka, Parreira \& Shitsuka (2018), em que tanto se propôs a analisar o desempenho dos estudantes nas edições do Enade, especificamente, nas questões de Educação Inclusiva relacionadas a pessoas com deficiência, quanto análise psicométrica das questões: i) classificar (análise por pares) as questões de acordo com a dimensão cognitiva da Taxonomia de Bloom Revisada (Anderson et al., 2001), ii) índice de facilidade e iii) índice de discriminação das questões. Foram considerados os mesmos valores de índice de facilidade utilizado no Enade: Muito fácil $\geq 0,86$; Fácil $(0,61$ a 0,85); Médio (0,41 a 0,60); Difícil $(0,16$ a 0,40$)$; Muito difícil $(\leq 0,15)$. Da mesma forma ocorreu para o índice de discriminação: Muito Bom ( $\geq 0,40)$; Bom (0,30 a 0,39); Médio (0,20 a 0,29); Fraco $(\leq 0,19)$.

Considerando cada edição do exame foram obtidos os seguintes números de participantes: 2004 (9.788); 2007 (10.582); 2011 (18.041); 2014 (23.208); 2017 (27.519). Como critério de exclusão, optou-se por excluir candidatos que deixaram algum item em branco e/ou não preencheu as informações do candidato, como, por exemplo, indicação de gênero, categoria administrativa e região geográfica, sendo esses três últimos às categorias utilizadas para comparações de resultados.

Para tanto foi utilizado o banco de dados do Enade das edições de 2004 a 2017, disponibilizados em forma de microdados no site do INEP (http://portal.inep.gov.br/microdados). Ao analisar as provas foram identificadas 9 questões de múltipla escolha sobre Educação Inclusiva relacionadas a pessoas com deficiência.

Para análise estatística das questões utilizou-se o programa SPSS versão 22.0. As questões (q.) selecionadas foram de múltipla escolha, especificamente da edição 2004 (q.27 e 28), 2007 (q.40), 2011 (q.17), 2014 (q.11 e q.19) e 2017 (q.13, q19 e q.32) para as quais foi realizada estatística descritiva para verificar o percentual de acertos e erros dos estudantes nas 
questões, considerando gênero (masculino e feminino), categoria administrativa (pública e privada) e regiões geográficas (Norte, Nordeste, Sudeste, Sul e Centro-Oeste). A questão 40 da edição de 2007 é de caráter discursiva/aberta compreendendo o resultado em uma escala de "acerto" de 0 a 100. Diante disso, para esse estudo considerou-se um resultado "não satisfatório" as notas obtidas $\leq 49,9$ e "satisfatório" as notas obtidas $\geq 50$.

Esta pesquisa segue as recomendações das normas estabelecidas na Resolução $\mathrm{n}^{\circ}$ 510/16 nos termos do Art. $1^{\circ}$, cláusula "V - pesquisa com bancos de dados, cujas informações são agregadas, sem possibilidade de identificação individual" e "VI - pesquisa realizada exclusivamente com textos científicos para revisão da literatura científica, não sendo necessária a submissão desta ao Comitê de Ética em Pesquisa” (Brasil, 2016).

\section{Resultados}

\subsection{Resultados da revisão integrativa}

Com a utilização das combinações de descritores foram encontrados 57 trabalhos no SciELO, 212 no LILACS, 138 no BDTD e 1168 no ERIC, totalizando 1575. Desses foram excluídos 1464 por título, 37 por não contemplar o recorte temporal, 2 por se tratar de uma revisão de literatura sistematizada e 5 por duplicação entre as bases de dados. Por fim, foram excluídos 35 e 18 após a leitura do resumo e na íntegra, respectivamente. Contudo, restaram 14 trabalhos ao final desse processo para serem analisados e discutidos de forma crítica. $\mathrm{O}$ número de artigos selecionados e excluídos podem ser melhores compreendidos no Fluxograma 1.

Fluxograma 1. Processo percorrido para seleção dos artigos para análise final. 

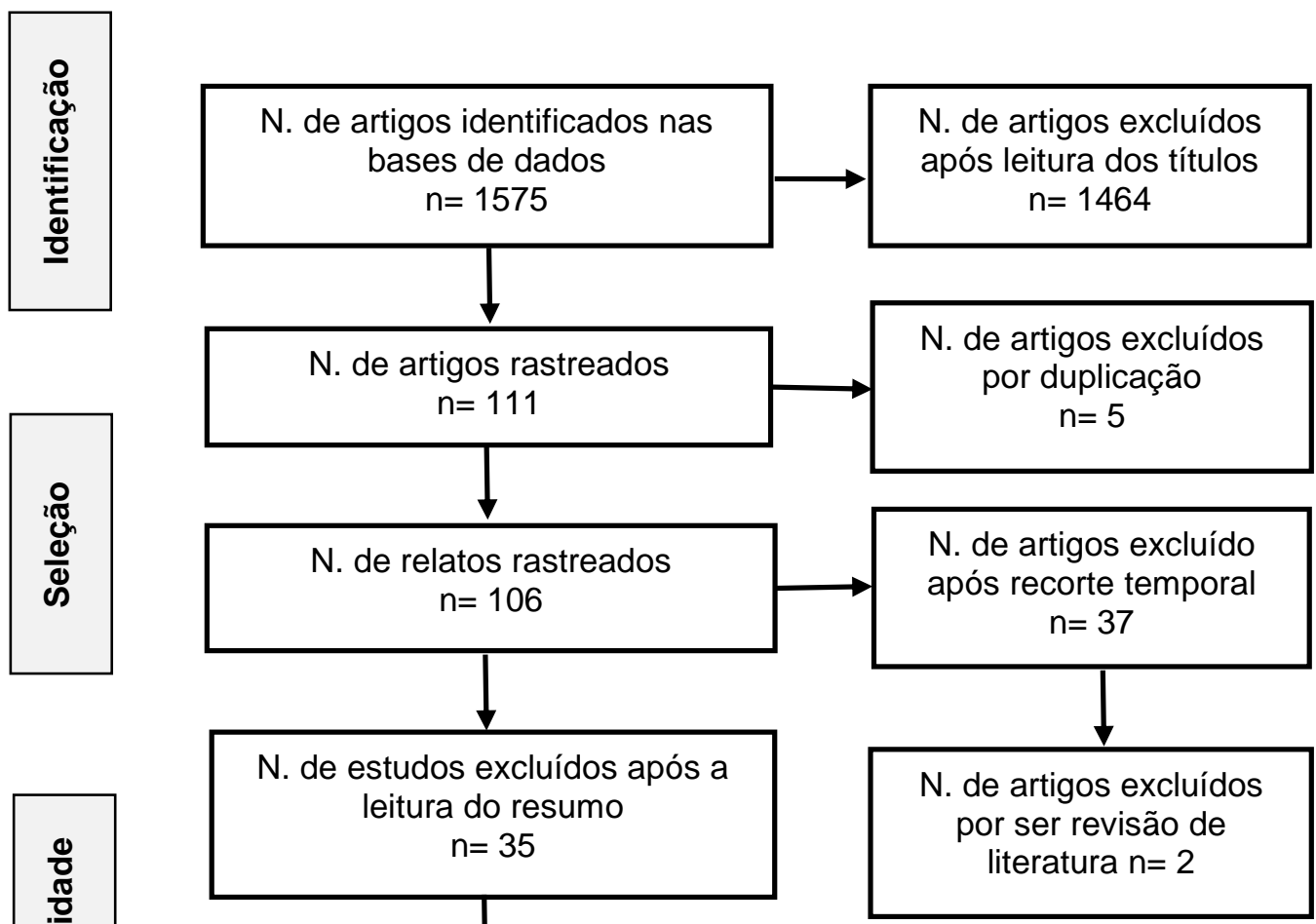

N. de artigos excluídos após a leitura na íntegra $\mathrm{n}=18$

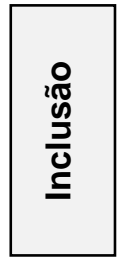

N. de estudos incluídos para síntese qualitativa $\mathrm{n}=14$

Fonte: Elaboração Própria.

Como podemos perceber no fluxograma acima, apenas 14 produções foram selecionadas para análise final, sendo esta etapa qualitativa e em pares. Destacamos que as demais produções científicas que não foram selecionadas para análise final, por não contemplar a pergunta principal dessa revisão integrativa, podem ser consultadas pelos profissionais ou interessados ao discutir ou investigar temas específicos que abordem a Educação Física e Educação Inclusiva. 
Res., Soc. Dev. 2019; 8(7):e11871106

ISSN 2525-3409 | DOI: http://dx.doi.org/10.33448/rsd-v8i7.1106

Na Tabela 1 observam-se os principais apontamentos das produções selecionadas em relação a Educação Inclusiva. Como é possível perceber, após a leitura, formulou-se 3(três) categorias, sendo elas, i) Formação, ii) Atuação e iii) Recursos (físicos e didáticos).

Tabela 1. Principais apontamentos dos estudos acerca da formação, atuação e recursos em Educação Física para atender alunos deficientes.

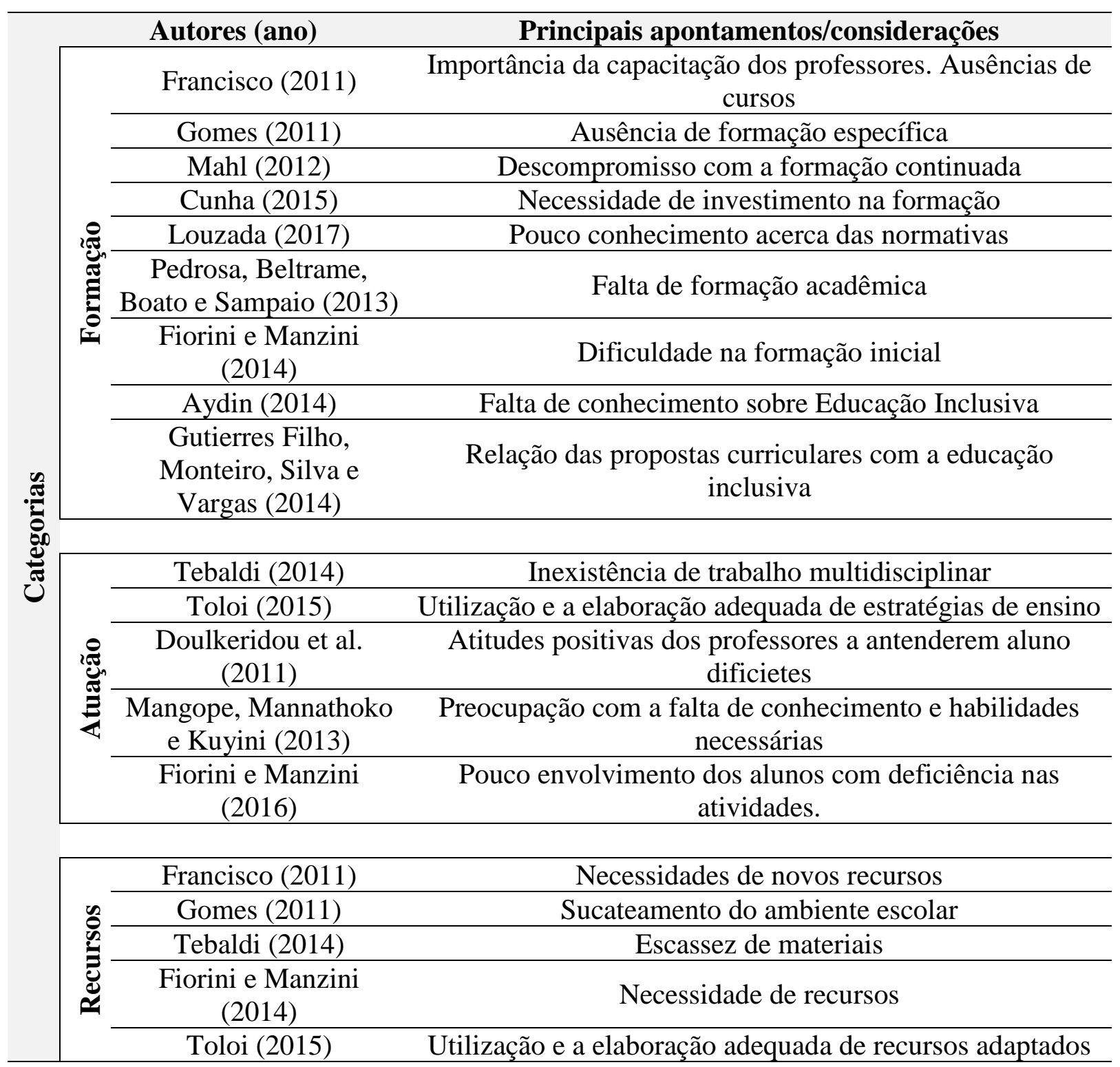

Fonte: Elaboração Própria.

Em relação a "formação" podemos identificar por meio da Tabela 1 que os estudos apontam para uma importância da capacitação dos professores, bem como assinalam algumas dificuldades existente na área quanto a prática de pessoas deficientes, como, por exemplo, a 
ausências de cursos, pouco conhecimento acerca das normativas e escassez de materiais para desenvolver atividades para esse público.

\subsection{Resultados das Análises dos microdados e psicométrica das questões}

Após apresentar o que vem sendo discutido sobre atuação e formação de professores para a Educação Inclusiva, sobretudo em Educação Física, agora é a vez de apresentar os resultados da análise psicométrica e os indicadores de desempenho dos estudantes dessa área nas questões acerca da Educação Inclusiva relacionada a pessoas com deficiência, no exame.

Na Tabela 2 podem ser consultados os resultados da análise psicométrica, em que constatamos na maioria dos itens índices de facilidade "Médio e "Difícil", índices de discriminação "Bom" ou "Muito bom" e de níveis "aplicar ou superior" na Taxonomia de Bloom Revisada.

Tabela 2. Índice de Facilidade e Índice de Discriminação (Ponto Bisserial) das questões de múltipla escolha.

\begin{tabular}{ccccccc}
\hline \multirow{2}{*}{ Ano } & \multirow{2}{*}{ Questão } & \multirow{2}{*}{ TBR } & \multicolumn{2}{c}{ Índice de Facilidade } & \multicolumn{2}{c}{ Índice de Discriminação } \\
\cline { 3 - 7 } & & & Valor & Classificação & Valor & Classificação \\
\hline \multirow{2}{*}{2004} & q.27 & Aplicar & 0,41 & Médio & 0,46 & Muito bom \\
& q.28 & Aplicar & 0,45 & Médio & 0,47 & Muito bom \\
\hline \multirow{2}{*}{2011} & q.17 & Entender & 0,24 & Difícil & 0,11 & Fraco \\
\hline \multirow{2}{*}{2014} & q.11 & Avaliar & 0,55 & Médio & 0,35 & Bom \\
& q.19 & Analisar & 0,67 & Fácil & 0,43 & Muito bom \\
\hline \multirow{2}{*}{2017} & q.13 & Lembrar & 0,50 & Médio & 0,27 & Médio \\
& q.19 & Entender & 0,72 & Fácil & 0,47 & Muito bom \\
& q.32 & Aplicar & 0,37 & Difícil & 0,33 & Bom \\
\hline
\end{tabular}

Fonte: Elaboração própria.

Quanto a quantidade de itens relacionado a Educação Inclusiva de pessoas deficientes física nas edições do ENADE, especificamente, nas provas dos estudantes do curso de licenciatura em Educação Física, podemos apontar uma média de dois itens por edição, sendo em 2017 a única a comportar três itens. Essa quantidade pode ser razoável, uma vez que o 
exame é composto por apenas 40 (quarenta) itens de formação específica, em que também objetiva avaliar outros conteúdos relevantes da área.

A Tabela 3 apresenta o desempenho dos estudantes nas questões selecionadas. Percebe-se que o percentual de acerto dos avaliados na maioria das questões está abaixo de 50\%. O gênero feminino mostrou um melhor desempenho em todas as edições, exceto na questão 11 da edição de 2014.

Tabela 3. Percentual de acerto dos avaliados nas questões de múltipla escolha por gênero, categoria administrativa e regiões geográficas.

\begin{tabular}{|c|c|c|c|c|c|c|c|c|c|c|}
\hline \multirow{3}{*}{\multicolumn{2}{|c|}{ Variáveis }} & \multicolumn{9}{|c|}{ Ano/Questão } \\
\hline & & \multicolumn{2}{|c|}{2004} & \multirow{2}{*}{\begin{tabular}{|l|}
2011 \\
$q .17$
\end{tabular}} & \multirow{2}{*}{$\frac{2007 *}{\text { q. } 40}$} & \multicolumn{2}{|c|}{2014} & \multicolumn{3}{|c|}{2017} \\
\hline & & q. 27 & q.28 & & & q.11 & q.19 & q. 13 & q.19 & q.32 \\
\hline \multirow{2}{*}{ Gênero } & Masculino & 37,3 & 42,1 & 23,4 & 13,1 & 56,0 & 64,9 & 48,2 & 72,1 & 35,9 \\
\hline & Feminino & 47,0 & 50,1 & 24,9 & 19,3 & 55,3 & 70,7 & 52,7 & 73,5 & 38,5 \\
\hline \multirow{2}{*}{$\begin{array}{c}\text { Categoria } \\
\text { administrativa }\end{array}$} & Pública & 49,4 & 52,6 & 26,8 & 14,8 & 61,4 & 71,0 & 52,6 & 74,0 & 38,7 \\
\hline & Privada & 38,6 & 43,0 & 23,2 & 16,1 & 53,6 & 66,3 & 49,4 & 72,4 & 36,5 \\
\hline \multirow{5}{*}{$\begin{array}{l}\text { Regiões } \\
\text { geográficas }\end{array}$} & Norte & 51,0 & 52,4 & 21,2 & 19,3 & 54,3 & 60,7 & 51,8 & 71,6 & 32,6 \\
\hline & Nordeste & 44,3 & 44,1 & 24,7 & 10,3 & 59,0 & 67,8 & 53,1 & 74,6 & 37,2 \\
\hline & Sudeste & 39,9 & 44,3 & 24,3 & 17,5 & 54,9 & 67,7 & 50,5 & 73,1 & 37,2 \\
\hline & Sul & 42,9 & 47,7 & 23,3 & 15,0 & 55,5 & 69,9 & 46,9 & 70,3 & 38,2 \\
\hline & $\begin{array}{l}\text { Centro- } \\
\text { Oeste }\end{array}$ & 45,6 & 51,2 & 24,5 & 13,1 & 54,6 & 66,9 & 50,1 & 75,6 & 36,0 \\
\hline
\end{tabular}

Fonte: Próprios autores com base em dados do Inep (BRASIL, 2004, 2011, 2014 e 2017). Legenda:* Os valores correspondem à quantidade de candidatos que obtiveram resultado satisfatório $(\geq 50)$.

Ainda em relação a Tabela 3, especificamente no que diz respeito a categoria administrativa, verificou-se um maior desempenho por parte das IES públicas em todas as edições. Quanto as regiões geográficas, evidenciou-se um melhor desempenho das regiões Nordeste e Norte.

\section{Discussão}

A atuação e a formação são docentes são processos indissociáveis das práticas educação inclusiva, porém reconhecemos que recursos materiais, gestão escolar, 
remuneração, condições da estrutura física das escolas são fatores que impactam o desenvolvimento de uma educação inclusiva de qualidade.

Assim como foi apresentado por Gomes (2011) na realidade Viçosa-MG, alguns elementos como o sucateamento das escolas, ausência de formação específica dos professores de Educação Física para trabalhar com alunos com deficiência não contribuem para boas práticas docentes. Corroborando, Souza (2018) destaca que como o aumento do ingresso de estudantes deficientes nas turmas regulares de ensino passa a se exigir mais por uma escola preparada tanto em recursos humanos, quanto em estrutura física.

A formação permanente, em que deveria ser considerada e exercida por todos os professores como recurso que oportuniza a aprendizagem das práticas pedagógicas, nem sempre é de alcance ou de objetivo para os profissionais. Consequentemente, a reflexão prático-reflexiva e as trocas de experiências deixam de ser vivenciadas, contribuindo para utilização de práticas desatualizadas e/ou inadequadas, além de tomadas de decisões ineficientes no contexto de sala de aula.

Formações continuadas para esses profissionais poderiam ser ofertadas ou organizadas pela própria gestão da escola ou pelas secretarias de Educação dos municípios, embora o trajeto a ser percorrido para um melhor atendimento dos alunos com deficiência não se limite apenas à prática dos professores. Para Cortelazzo (2012) os estudantes dos cursos de licenciaturas têm se envolvido em poucas atividades que poderiam estar agregando experiências necessárias para atuar com tais estudantes.

Nesse sentido, Pedrosa, Beltrame, Boato e Sampaio (2013) ao investigar experiências dos professores de Educação Física e sua formação para atuar com alunos surdos, evidenciaram que um número expressivo dos professores não teve em sua graduação disciplinas e nem conteúdos acerca da atuação com esse público. Tal realidade pode ser encontrada em outras localidades do país, até mesmo de forma mais preocupante. 
Res., Soc. Dev. 2019; 8(7):e11871106

ISSN 2525-3409 | DOI: http://dx.doi.org/10.33448/rsd-v8i7.1106

Ao analisar o desempenho dos estudantes no Enade nas questões de Educação Inclusiva, destaca-se um maior resultado por parte dos estudantes de IES da região Nordeste e Norte. O melhor desempenho dessas regiões pode estar relacionado a fatores culturais, como a maior população e estudantes com deficiência, assim como mostrou a Cartilha do Censo 2010 para pessoa com deficiência (Brasil, 2012). A Cartilha apontou a região Nordeste e Norte $(26,63 \%$ e $23,40 \%)$ com maior proporção da população com pelo menos umas das deficiências investigadas: deficiências visual, auditiva, motora e mental ou intelectual. Já as regiões Sul e Centro-Oeste $(22,50 \%$ e $22,51 \%)$ apresentaram com números proporcionais menores que aquelas regiões.

Diante dessa realidade, não só aumenta o número de políticas, como também a importância dos cursos de Educação Física da região Nordeste e Norte enfatizar na formação inicial experiências indispensáveis para as demandas desse público. Somado a isso, o interesse dos alunos com os conhecimentos da Educação Inclusiva pode estar influenciado pela preocupação em obter condições de ofertar um melhor ensino e/ou aumentar as possibilidades de ingresso no mercado de trabalho.

Estudo desenvolvido por Lustosa (2018) observou que a pesquisa na área de Educação Especial na região Nordeste se concentra em poucos pesquisadores e linhas de pesquisas dos programas de pós-graduação stricto sensu. Frente a isso ressaltamos a necessidade de aumentar a quantidade e qualidade dos conhecimentos já produzidos para que venham subsidiar as práticas docentes, uma vez que pesquisadores, não só da área de Educação Física, vêm alertando para melhoria da formação dos professores para atuar na Educação Inclusiva (González, Alba, \& Mesa, 2018; Louzada, 2017; Fiorini \& Manzini, 2016).

É importante um curso pautado nos aspectos relacionados à atividade física e ao ensino de pessoas com deficiência para o fortalecimento profissional dos professores de Educação Física, tornando necessários mecanismos que apoiem a ação profissional e os 
desafios educacionais e sociais que serão vivenciados em suas práticas, bem como contribuindo na formação de um profissional com senso crítico e participativo (Borella, 2010).

Oliveira (2011) ressalta o desafio em formar professores preparado para atuar igualmente frente à diversidade de seus alunos, seja ele com deficiência ou não, e também a importância de não entender a deficiência como uma incapacidade. Para isso, o autor defende a necessidade de uma formação sólida, que dê subsídios à prática profissional através da base teórica, pautada em valores humanistas e na reflexão-ação-reflexão crítica. Assim, o conhecimento é compreendido como fonte primordial para o embasamento das práticas e possibilita a compreensão por parte dos acadêmicos e profissionais de Educação Física, de que para transformar torna-se necessário a participação em cursos de formação continuada.

Nesse sentido, o curso de Educação Física pode colaborar quando sua proposta curricular dinâmico e diversificado, contemplando, não somente atividades no âmbito técnico, científico, mas também cultural e de caráter prático, proporcionando ao acadêmico a aquisição de novos conhecimentos e possibilidades para o embasamento de suas futuras práticas (Neira \& Borges, 2018).

A formação inicial dos profissionais de Educação Física é um dos aspectos primordiais para que o processo de inclusão ocorra efetivamente. Entendemos, também que a formação em educação para atuar com pessoas com deficiência deve ser parte integrante da formação básica de professores, não sendo destacada apenas como uma subárea ou um campo específico.

\section{Considerações Finais}

Chegando as considerações finais dessa investigação, a qual objetivou avaliar os conteúdos e o desempenho de estudantes de Educação Física nos itens de Educação Inclusiva no ENADE, e que também por meio de uma revisão integrativa apontou diferentes dilemas 
Res., Soc. Dev. 2019; 8(7):e11871106

ISSN 2525-3409 | DOI: http://dx.doi.org/10.33448/rsd-v8i7.1106

sobre a formação e atuação dos professores da referida área, fica evidente o quanto pesquisas como essa pode incentivar no desenvolvimento e aprimoramento dos conteúdos teóricos e práticos acerca da Educação Inclusiva para pessoas com deficiência na formação e atuação de professores de Educação Física.

Percorrido o caminho traçado inicialmente, pode-se afirmar a partir dessa investigação que a formação e atuação dos professores de Educação Física na Educação Inclusiva de pessoas com deficiência pouco vêm sendo discutido na literatura científica. Além disso, os estudos apontam críticas nas três categorias formuladas pela revisão integrativa: "Formação" (ausência de formação específica, descompromisso com a formação continuada); "Atuação" (inexistência de trabalho multidisciplinar, pouco envolvimento dos alunos com deficiência nas atividades) e "Recursos" (necessidades de novos recursos, escassez de materiais).

A temática Educação Inclusiva de pessoas deficientes foi abordada em 9 questões ao longo das cinco edições que compreendem o Enade de Licenciatura em Educação Física. Com base nos levantamentos, observou que $50 \%$ das questões possuem índice de facilidade "Médio" e índice de discriminação "Muito bom", detectando apenas um item considerado "Fraco".

Quanto à complexidade das questões na estrutura cognitiva da Taxonomia de Bloom Revisada, embora identificadas questões no nível "Analisar", não foi identificada nenhuma nos últimos níveis avaliar e criar. Ou seja, é necessário um aumento de questões que envolvam criar, elaborar ideias com o objetivo de uma avaliação mais condizente com situações do cotidiano ao exercer a profissão.

Em relação ao desempenho foram evidenciados baixos percentuais de acerto nas questões selecionadas, sendo predominantemente abaixo de 50\%. No entanto é possível destacar o desempenho satisfatório dos estudantes do gênero feminino, de IES públicas e de 
Res., Soc. Dev. 2019; 8(7):e11871106

ISSN 2525-3409 | DOI: http://dx.doi.org/10.33448/rsd-v8i7.1106

estudantes de IES localizadas na região Nordeste e Norte, o que pode estar relacionado com as características socioculturais e demanda quanto ao público investigado.

A formação inicial dos professores é um elemento fundamental para que a Educação Inclusiva ocorra na sua efetividade, de modo que o profissional se sinta apto a ensinar pessoas com deficiência. Entendendo o Enade como um mecanismo importante na verificação de desempenho na formação inicial, torna-se necessário um maior comprometimento das IES e dos estudantes com os conhecimentos teóricos e práticos que fundamentam essa temática no contexto acadêmico e na intervenção social.

Por fim, sugerimos trabalhos futuros que objetivem analisar os Projetos Pedagógicos dos Cursos (PPC's), bem como as ementas dos cursos de Educação Física, de forma apontar indicativos de como a Educação Inclusiva vem sendo discutida na formação inicial dos professores dessa área em diferentes contextos/realidades.

\section{Referências}

Anderson, L. W. et al. (2001). A taxonomy for learning, teaching and assessing: a revision of Bloom's Taxonomy of Educational Objectives. Book Review - Educational Horizons. Nova York: Addison Wesley Longman, 154. Recuperado de: https://45afdf87-a62cb3a1 assites.googlegroups.com/site/ramirodotcom/home/true/

Bloomtaxonomiadosobj ectivoseducacionais.pdf.

Aydin, M. (2014). Assessing Knowledge Levels of Secondary School Physical Education and Sports Teachers about Inclusive Education. Educational Research and Reviews, 9, (21), 1115-1124. Recuperado de https://eric.ed.gov/?id=EJ1045520.

Borella, D. R. (2010). Atividade física adaptada no contexto das matrizes curriculares dos cursos de Educação Física. 164 f. Tese (Doutorado em Educação Especial) - Centro de Educação e Ciências Humanas, Universidade Federal de São Carlos.

Brasil (2009). Decreto n. 6.949, de 25 de agosto de 2009. Promulga a Convenção Internacional sobre os Direitos das Pessoas com Deficiência e seu Protocolo Facultativo. Diário Oficial da União, Brasília, 26 ago.

Brasil (1996). Lei de diretrizes e bases da Educação Nacional, n. 9394. Brasília: MEC, 1996. 
Brasil (2010). Ministério da Educação. Conselho Nacional de Educação. Câmara de Educação Básica. Resolução $n^{o} 4$, de 13 de julho de 2010. Define Diretrizes Curriculares Nacionais Gerais para a Educação Básica. Diário Oficial da União, Brasília, 14 jul.

Brasil (2010). Cartilha do Censo 2010: Pessoas com deficiência. Coordenação-Geral do Sistema de Informações sobre a Pessoa com Deficiência; Brasília: SDH-PR/SNPD, 2012. Recuperado de: http://www.portalinclusivo.ce.gov.br/phocadownload/cartilhasdeficiente/cartilha-censo2010-pessoas-com-deficiencia.pdf.

Brasil (2016). Ministério da Saúde. Conselho Nacional de Saúde. Resolução $n^{\circ}$ 510, de 7 de abril de 2016. Diário Oficial [da] República Federativa do Brasil, Brasília, DF, 24 maio. Seção 1, 44-46. Recuperado de: http://conselho.saude.gov.br/resolucoes/2016/reso510.pdf.

Brasil (2014). Presidência da República. Casa Civil. Lei n. 13.005, de 25 de junho de 2014. Aprova o Plano Nacional de Educação - PNE e dá outras providências. Diário Oficial da União, Brasília, DF, 26 jun. Recuperado em http://www.planalto.gov.br/ccivil_03/_ato2011-2014/2014/lei/13005.htm.

Cortelazzo, I. B. C. (2012). Formação de professores para uma Educação Inclusiva mediada pelas tecnologias. p. 93-120. In: Giroto, C. R. M.; Poker, R.B.; Omote, S. (org). As tecnologias nas práticas pedagógicas inclusivas. Marília: Cultura Acadêmica, 238p.

Cunha, R. F. P. (2015). Educação física escolar: concepções e princípios sobre inclusão escolar de professores da Rede Municipal de Fortaleza. 128f. Dissertação (Mestrado) Universidade Federal do Ceará, Programa de Pós-graduação em Educação Brasileira, Fortaleza (CE), 2015. Recuperado de: http://www.repositorio.ufc.br/handle/iufc/14646.

Doulkeridou, A. et al. (2011). Attitudes of Greek Physical Education Teachers towards Inclusion of Students with Disabilities in Physical Education Classes. International Journal of Special Education, 26 (1), 1-11, Recuperado de: https://eric.ed.gov/?id=EJ921174.

Fiorini, M. L. S., \& Manzini, E. J. (2016). Dificuldades e Sucessos de Professores de Educação Física em Relação à Inclusão Escolar. Rev. bras. educ. espec, 22 (1), 49-64. doi: http://dx.doi.org/10.1590/S1413-65382216000100005.

Fiorini, M. L. S., \& Manzini, E. J. (2014). Inclusão de alunos com deficiência na aula de educação física: identificando dificuldades, ações e conteúdo para prover a formação do professor. Rev. bras. educ. espec. 20 (3), 387-404. doi: ttp://dx.doi.org/10.1590/S141365382014000300006.

Francisco, A. B. (2011). Educação física escolar para alunos com deficiência incluídos na rede estadual de ensino em São Paulo. 73 f. Dissertação (Mestrado em Psicologia) Universidade Presbiteriana Mackenzie, São Paulo. 
Galvan, J. L. (2017). Writing Literature Reviews: A Guide for Students of the Social and Behavioral Sciences. 7th Edition, Kindle Edition.

Galvão, T. F., Pansani, T. S. A., \& Harrad, D. (2015). Principais itens para relatar Revisões sistemáticas e Meta-análises: A recomendação PRISMA. Epidemiol. Serv. Saúde, 24 (2), 335-342. doi: http://dx.doi.org/10.5123/S1679-49742015000200017.

González, P. C., Alba, B. G., \& Mesa, M. F. S. (2018). Agrupamientos escolares y retos para la educación inclusiva en infantil y primaria. Tendencias Pedagógicas, 32, inicial-final. doi: $10.15366 /$ tp2018.32.006.

Gomes, D. P. (2011). Os sentidos da inclusão de alunos com deficiência no discurso dos professores de educação física. 102 f. Dissertação (Mestrado em Aspectos sócioculturais do movimento humano; Aspectos biodinâmicos do movimento humano) Universidade Federal de Viçosa, Viçosa.

Gutierres Filho, P. J. B., Monteiro, M. D. A. F., Silva, R., \& Vargas, C. R. (2014). Aspectos curriculares da formação universitária em educação física para atuação na educação inclusiva. Revista Pensar a Prática, 17 (1), 81-99. doi: https://doi.org/10.5216/rpp.v17i1.19578.

Louzada, J. C. A. (2017). Inclusão Educacional: em foco a Inclusão Educacional: em foco a formação de professores de Educação Física. 127f. Dissertação (Mestrado em Educação) - Universidade Estadual Paulista (Unesp), Faculdade de Filosofia e Ciências. Recuperado de: https://repositorio.unesp.br/handle/11449/148984.

Lustosa, A V. M. F. (2018). Teses e dissertações em Educação Especial na região nordeste no período de 1997 a 2012. Revista Educação Especial, 31 (60), 51-64. Doi: http://dx.doi.org/10.5902/1984686X18997.

Mahl, E. (2012). Práticas pedagógicas dos professores de educação física frente à inclusão de alunos com deficiência. 156 f. Dissertação (Mestrado em Ciências Humanas) Universidade Federal de São Carlos, São Carlos.

Mangope, B., Mannathoko, M. C., \& Kuyini, A. B. (2013). Pre-service physical education teachers and inclusive education: attitudes, concerns and perceived skill needs. International Journal of Special Education, 28 (3), 82-92. Recuperado de: https://eric.ed.gov/?id=EJ1024424.

Neira, M. G., \& Borges, C. C. O. (2018). Esquadrinhar e Governar: análise das recomendações do CONFEF para a Educação Física escolar. Educação \& Realidade, Porto Alegre, 43, (2), 571-590. Doi: http://dx.doi.org/10.1590/2175-623664150.

Noronha, E. G., \& Pinto, C. L. (2014). Educação Especial e Educação Inclusiva: aproximações e convergências. Católica Online, Cuiabá-MT. Recuperado de http://www.catolicaonline.com.br/semanapedagogia/trabalhos_completos. 
Oliveira, J. D. B. (2011). Educação Física Especial e currículo: (in) formação para a educação inclusiva. 308 f. Tese (Doutorado em Educação) - Faculdade de Educação, Universidade Federal da Bahia, Salvador.

Pedrosa, V. S., Beltrame, A. L. N., Boato, É. M., \& Sampaio, T. M. V. (2013). A experiência dos professores de educação física no processo de inclusão escolar do estudante surdo. Revista Brasileira de Ciência e Movimento, 21 (2), 106-125. doi: http://dx.doi.org/10.18511/0103-1716/rbcm.v21n2p106-115.

Pereira, A. S., Shitsuka, D. M., Parreira, F. J., \& Shitsuka, R. (2018). Metodologia da pesquisa científica. 1. ed. - Santa Maria, RS: UFSM, NTE, 2018.

Pletsch, M. D., \& Souza, F. F. (2017). Fórum Permanente de Educação Especial da Baixada Fluminense: pesquisa e extensão na formação de professores. Inc. Soc., Brasília, DF, 11 (1), 46-55. Recuperado de: http://revista.ibict.br/inclusao/article/view/4078/3590.

Silva Neto, A. O., Ávila, É. G., Sales, T. R. R., Amorim, S. S., Nunes, A. K. F., Santos, V. M. (2018). Educação inclusiva: uma escola para todos. Revista Educação Especial, 31 (60), 81-92. doi: http://dx.doi.org/10.5902/1984686X24091.

Sousa, K. C. (2017). A formação docente para a educação especial e a prática profissional do professor. 98 f. Dissertação (Mestrado em Docência e Gestão da Educação) Faculdade de Ciências Humanas e Sociais, Universidade Fernando Pessoa, Porto.

Souza, A. M. (2018). As práticas pedagógicas e a inclusão dos estudantes com necessidades educacionais específicas - NEES. Tendências Pedagógicas, (31), 97-111. doi: http://dx.doi.org/10.15366/tp2018.31.005.

Tebaldi, M. (2014). Formação continuada em educação física e inclusão do deficiente no ensino regular sob a ótica de professores. 153 f. Dissertação - (mestrado) Universidade Estadual Paulista, Instituto de Biociências de Rio Claro.

Thomas, J. R., Nelson, J. K., \& Silverman, S. J. (2012). Métodos de pesquisa em atividade física. $6^{\mathrm{a}}$ ed. Porto Alegre: Artmed.

Toloi, G. G. (2015). Formação de professores de educação física para inclusão educacional usando tecnologia assistiva. $212 \mathrm{f}$. Tese (doutorado) - Universidade Estadual Paulista Júlio de Mesquita Filho, Faculdade de Filosofia e Ciências. Recuperado de https://repositorio.unesp.br/handle/11449/123890.

\section{Porcentagem de contribuição de cada autor no manuscrito}

Antonio Evanildo Cardoso de Medeiros Filho - 30\%

José Airton de Freitas Pontes Junior - 20\%

Luciana Fialho Rocha Santa Rosa - 20\% 
Res., Soc. Dev. 2019; 8(7):e11871106

ISSN 2525-3409 | DOI: http://dx.doi.org/10.33448/rsd-v8i7.1106

Kélvia Sena de Santana - 15\%

Rita de Cássia Barbosa Paiva Magalhães - 15\% 